\title{
Correction to: Incidence and Risk Factors for Cholelithiasis After Bariatric Surgery
}

\author{
Hernán Guzmán M. ${ }^{1}$ - Matías Sepúlveda ${ }^{1,2}$ (1) Nicolás Rosso ${ }^{3}$. Andrés Esteban San Martin ${ }^{2}$. \\ Felipe Guzmán ${ }^{4}$. Hernán Guzmán C. ${ }^{1,2}$
}

Published online: 28 May 2019

(C) Springer Science+Business Media, LLC, part of Springer Nature 2019

\section{Correction to: Obesity Surgery https://doi.org/10.1007/s11695-019-03760-4}

Due to a metadata tagging error the name of author Andrés Esteban San Martín was indexed incorrectly. The author's given name is Andrés Esteban and his family name is San Martín.

Publisher's Note Springer Nature remains neutral with regard to jurisdictional claims in published maps and institutional affiliations.

The online version of the original article can be found at https://doi.org/ 10.1007/s11695-019-03760-4

Matías Sepúlveda

drmsepulveda@gmail.com

Hernán Guzmán M.

hernus87@gmail.com

Nicolás Rosso

nicorosso@gmail.com

Andrés Esteban San Martin

andresesanmartin@gmail.com

Felipe Guzmán

felipe.igm26@gmail.com
Hernán Guzmán C.

hguzmanc@mi.cl

1 Bariatric and Metabolic Surgery Center, DIPRECA Hospital, Vital Apoquindo 1200, Las Condes, Santiago, Chile

2 Escuela de Medicina, Universidad Diego Portales, Av. Ejército Libertador 141, Santiago, Chile

3 Hospital San Camilo, Miraflores 2085, San Felipe, Santiago, Chile

4 Escuela de Medicina, Universidad de Santiago, Av Libertador Bernardo O’Higgins 3363, Santiago, Chile 